\title{
Caracterização do Regime de Ventos no Piaú Para o Aproveitamento de Energia Eólica
}

\author{
Marcos Antonio Tavares Lira ${ }^{1}$, José Machado Moita Neto ${ }^{2}$, João Victor Lopes de Loiola ${ }^{3}$, \\ Emerson Mariano da Silva ${ }^{4}$, José Maria Brabo Alves ${ }^{4}$ \\ ${ }^{1}$ Departamento de Engenharia Elétrica, Universidade Federal do Piauí, Teresina, PI, Brasil. \\ ${ }^{2}$ Programa de Pós-Graduação em Desenvolvimento e Meio Ambiente, \\ Universidade Federal do Piaui, Teresina, PI, Brasil. \\ ${ }^{3}$ Programa de Pós-Graduação em Engenharia Elétrica, Universidade de Brasília, DF, Brasil. \\ ${ }^{4}$ Departamento de Física, Universidade Estadual do Ceará, Fortaleza, CE, Brasil.
}

Recebido em 7 de Dezembro de 2015 - Aceito em 15 de Dezembro de 2016

\begin{abstract}
Resumo
O presente estudo apresenta uma caracterização do regime de ventos em algumas regiões do estado do Piauí, realizada por meio da análise do perfil da velocidade média horária e mensal dos ventos bem como da freqüência da direção dos mesmos. O objetivo principal do trabalho é identificar possíveis sítios de geração de energia eólica no Piauí a partir do uso de uma ferramenta computacional: o software Windographer ${ }^{\circledR}$. Utilizando-se a base de dados do ano de 2010 do Instituto Nacional de Meteorologia (INMET) foram analisados os municípios de Valença, Floriano, Alvorada do Gurgueia, Oeiras, Caracol, São João do Piauí, Paulistana e Parnaíba. Para cada município são apresentados graficamente o regime de ventos horário e mensal bem como da sua direção predominante no período estudado. Os resultados mostraram que os municípios de Paulistana e Parnaíba se destacaram por apresentarem um potencial eólico satisfatório para o aproveitamento de energia elétrica.

Palavras-chave: regime de ventos, Windographer ${ }^{\circledR}$, energia eólica.
\end{abstract}

\section{Characterisation of Wind Behaviour in Piauí in Order to Utilize Wind Energy}

\begin{abstract}
This work presents the characterization of wind behaviour in some regions of Piauí through analyses of daily and monthly average wind speed and average wind direction. The main objective of this work is identifying potential wind power sites using Windographer ${ }^{\circledR}$ software. Areas of Piauí such as: Valença, Floriano, Alvorada do Gurgueia, Oeiras, Caracol, São João do Piauí, Paulistana e Parnaíba were analysed through the 2010 database provided by The National Institute of Meteorology (INMET). This work provides, for each region, graphs of daily and yearly wind behaviour. The results show that Paulistana e Parnaíba present a satisfactory wind potential to generate electricity.
\end{abstract}

Keywords: wind behaviour, Windographer ${ }^{\circledR}$, wind energy. .

\section{Introdução}

Devido à crise do petróleo na década de 70, as economias globais sentiram a necessidade de incorporar, novas fontes de energia às suas matrizes energéticas. Até 1985, os investidores em energia eólica na Dinamarca recebiam $30 \%$ do valor da compra das unidades como subsídio do governo. Em 1978, nos Estados Unidos, as turbinas eólicas foram legalmente autorizadas a se conectarem a rede e houve uma ampliação das linhas de créditos para aqueles que instalavam turbinas eólicas (Pinto, 2013). Assim como a eólica, outras fontes de energia, solar, biomassa e hidrogênio começaram a ganhar espaço no cenário global.

O número de parques eólicos instalados no Brasil cresceu rapidamente. Segundo a associação brasileira de energia eólica (ABEEólica), 241 usinas estavam instaladas

Autor de correspondência: Marcos Antonio Tavares Lira, marcoslira@ufpi.edu.br. 
no início de 2015. Tal fato evidencia a importância de estudos sobre o regime dos ventos, principalmente com o objetivo de identificar possíveis sítios de energia eólica e compreender o comportamento das massas de ar predominantes em determinadas regiões do país.

A possibilidade de aumento do aproveitamento dessa energia trouxe consigo um aumento na quantidade de recursos financeiros no setor. Em 2002, a potência instalada no país era de $22 \mathrm{MW}$. Em 2015 essa potência já atingiu 6.000 MW. O estado do Ceará foi um dos que mais investiu nessa fonte. Sua potência instalada passou de 17,4 MW para quase $1000 \mathrm{MW}$ neste mesmo período.

Para Castro (2006), quando se pensa no aproveitamento dos recursos eólicos para produção de energia é necessário que se leve em consideração todas as variáveis envolvidas: quantificação dos recursos eólicos (velocidade e direção dos ventos), a área afetada pela construção de uma usina eólica, as condições sociais, econômicas e culturais na população diretamente atingida, bem como os aspectos ambientais. Este "pensar" deve partir de uma visão estratégica na qual todas as possibilidades (riscos, dificuldades, pontos fortes e fracos) devem ser ponderadas antes mesmo da implementação de qualquer empreendimento.

O objetivo principal do trabalho é identificar possíveis sítios de geração de energia eólica no Piauí a partir da análise dos gráficos gerados pelo software Windographer ${ }^{\text {. }}$

\section{Revisão da Literatura}

\subsection{Aspectos físicos dos recursos eólicos}

De acordo com Ometto (1981), a ocorrência de áreas mais aquecidas, sobre as quais o ar atmosférico possui menor densidade, decorre do processo de aquecimento diferencial da superfície terrestre. Em contrapartida, regiões mais frias, possuem sobre si, ar atmosférico mais denso. A força resultante da necessidade do equilíbrio das diferentes densidades do ar atmosférico estabelece variações na pressão atmosférica, proporcionando o surgimento de gradientes de pressão de características horizontais. $\mathrm{O}$ gradiente de pressão estabelece o aparecimento de uma quantidade de movimento (momentum) na massa de ar, e essa quantidade de movimento tanto é maior quanto maior for o gradiente de pressão.

Segundo Varejão-Silva (2006), chama-se vento à componente horizontal representada na Eq. (1). O vetor velocidade do vento é representado pela Eq. (2).

$$
\begin{aligned}
& \overrightarrow{\mathrm{V}}=u \overrightarrow{\mathrm{i}}+v \overrightarrow{\mathrm{j}}+w \overrightarrow{\mathrm{k}} \\
& \overrightarrow{\mathrm{V}}_{x y}=u \overrightarrow{\mathrm{i}}+v \overrightarrow{\mathrm{j}}
\end{aligned}
$$

em que $u, v$ e $w$ são as componentes do vetor velocidade do vento nas direções $x, y$ e $z$, respectivamente $\mathrm{e}, \overrightarrow{\mathrm{i}}, \overrightarrow{\mathrm{j}}, \overrightarrow{\mathrm{k}}$ são os vetores unitários nessas direções. Para que o vento seja caracterizado em um ponto da atmosfera duas informações são essenciais: a sua direção e o módulo da sua velocidade. Estas grandezas são verificadas instantaneamente e de forma pontual, uma vez que o escoamento do ar está relacionado às condições atmosféricas, que variam no espaço e com o tempo. O vento sofre forte influência do relevo local, sobretudo na zona de fronteira entre superfície e atmosfera.

Ao se analisar os valores de velocidade e de direção dos recursos eólicos verifica-se uma variabilidade temporal destes dados, a qual pode ir desde uma variação diária até uma variação interanual.

Segundo Silva (2003), o vento pode ser mais intenso em algumas áreas que em outras, pode aumentar sua intensidade por alguns meses do ano, como pode aumentar apenas durante algumas horas do dia, e pode, também, parar por longos períodos ininterruptos. As variações de vento na escala de tempo podem ser divididas em duas grandes classes: variações lentas e variações rápidas.

Durante os dias ensolarados, a superfície do continente se aquece mais rapidamente que a do oceano adjacente. Como consequência surge uma faixa de pressão mais baixa sobre o litoral, acarretando o desenvolvimento de correntes convectivas ascendentes sobre o continente, as quais geram nuvens convectivas. Acima do oceano a pressão é elevada, face à menor temperatura da água à superfície. Dessa maneira, se estabelece uma circulação fechada, com movimentos ascendentes na costa e subsidentes sobre o mar.

$\mathrm{O}$ vento, à superfície, sopra do oceano para o continente, em direção aproximadamente perpendicular à linha da costa e é chamado brisa marítima (Varejão-Silva, 2006). Durante a noite o continente perde uma grande quantidade de calor mais rapidamente que o oceano e, a partir de certa hora após o pôr do Sol, a superfície do oceano apresenta uma temperatura mais elevada que a do continente. A faixa de baixa pressão se situa, então, sobre o oceano e o movimento ascendente associado a ela pode gerar nuvens convectivas. $\mathrm{O}$ vento passa a soprar do continente para o mar, à superfície, constituindo a brisa terrestre.

As brisas marítimas contribuem fortemente para um incremento na intensidade e na variação da direção dos Ventos Alísios, ventos de grande escala que atuam ao longo do globo terrestre; além de afetar a temperatura e a umidade do ar na região. As maiores incidências de brisas marítimas, geralmente, ocorrem nos meses de verão. A direção das brisas depende, fundamentalmente, da orientação da costa litorânea; sendo esta, no litoral, perpendicular à linha de praia (Silva, 2003).

$\mathrm{O}$ escoamento do ar assim como as turbulências em seu fluxo sobre uma determinada região da superfície terrestre são fortemente determinados pelo relevo e pela presença de obstáculos físicos em tal região. A ação da superfície terrestre na redução do torque dos ventos é descrita por uma propriedade física chamada rugosidade. A rugosidade da superfície ocasiona a redução da velocidade do ar (Martins et al., 2008). 
Além do comportamento turbulento devido às interações superfície-atmosfera, outro aspecto importante a ser considerado é o cisalhamento do vento (Martins et al., 2008). Na camada-limite superficial observa-se um perfil vertical aproximadamente logarítmico do módulo da velocidade do vento, como apresentado graficamente na Fig. 1.

A medição do vento deve ser efetuada a uma altura próxima daquela onde vai ser instalado o cubo do rotor da turbina. Por forma a permitir correlacionar os dados do local com os registos existentes em estações meteorológicas próximas é desejável uma medida adicional à altura normalizada de $10 \mathrm{~m}$.

Em última análise, na ausência de medições realizadas na altura onde ficarão as turbinas, a medição feita a $10 \mathrm{~m}$ nas estações meteorológicas de superfície nos dá uma estimativa da velocidade em outras alturas através da Eq. (3), a qual é uma extrapolação para alturas diferentes de dados medidos a uma altura de referência (Castro, 2006):

$$
v(z)=v\left(Z_{R}\right) \frac{\ln \left(\frac{Z}{Z_{0}}\right)}{\ln \left(\frac{Z_{R}}{Z_{0}}\right)}
$$

onde a variação da velocidade com a altura vertical $z, v(z)$, é dada em função da velocidade a uma altura de referência $v$ $\left(Z_{R}\right)$, do comprimento de rugosidade $\left(Z_{0}\right)$ e da própria altura de referência $Z_{R}$. O comprimento de rugosidade corresponde à altura em que o vento, próximo à superfície, assume valor zero, e depende do relevo e obstáculos da superfície. Contudo, o perfil real de velocidades na vertical depende também da variabilidade de temperatura e pressão na atmosfera (Martins et al., 2008).

\subsection{Aspectos ambientais da energia eólica}

A energia eólica é responsável por baixos impactos ambientais. Segundo Dutra (2012), devido ao uso da energia eólica não implicar em emissões de gases ou resíduos, não existir deslocamento de populações, não gerar alaga-

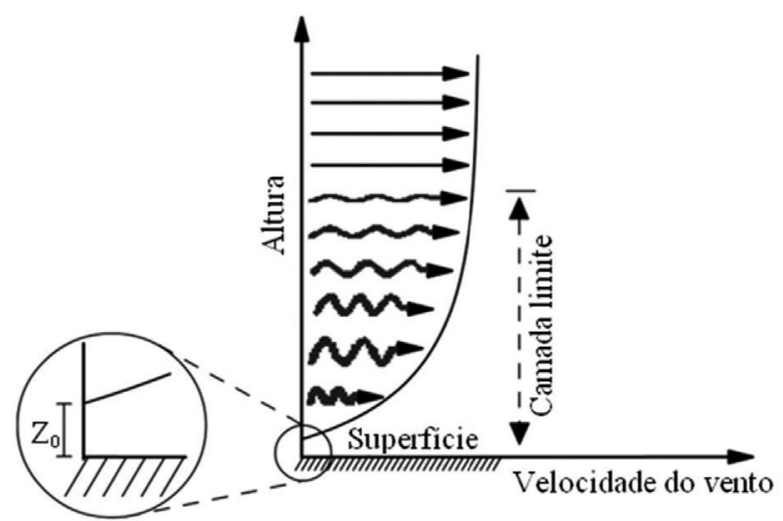

Figura 1 - Perfil vertical da velocidade do vento. O comprimento da rugosidade $\left(Z_{0}\right)$ é a altura onde a velocidade é nula. mentos de sítios arqueológicos e florestas e não inviabilizar a área utilizada, esta fonte de energia apresenta baixos impactos ambientais.

Um dos efeitos negativos gerados pela implantação de parques eólicos é a utilização do terreno. Em média gera-se $10 \mathrm{MW} / \mathrm{km}^{2}$ (Custódio, 2013). Embora a área de instalação seja grande, o solo efetivamente ocupado e muito pequeno.

Aerogeradores provocam impactos visuais. Devido ao fato de torres superarem alturas equivalentes $100 \mathrm{~m}$ e por operarem em áreas abertas, ocorre uma alteração na paisagem, que pode ser minimizada quando as mesmas são instaladas perto de estradas. Além disso, a sombra e o reflexo do aerogerador pode causar desconforto para os moradores próximos (Custódio, 2013). Embora os efeitos sejam mínimos, o ponto de instalação deve ser escolhido de forma a minimizar o impacto visual e o surgimento de sombras e reflexos.

Um problema comum causado pelas pás da turbina é o ruído. Segundo Berg (2006), especialmente durante a noite sob condições atmosféricas estáveis, é possível o surgimento de ondas com frequência de $4 \mathrm{~Hz}$. Custódio (2013) afirma que $400 \mathrm{~m}$ de distancia em relação a um aerogerador é uma distância segura, pois os ruídos são inferiores a $40 \mathrm{~dB}$. Mesmo gerando ondas de baixa frequência, os efeitos destas em pessoas devem ser cuidadosamente investigados.

Dentre os impactos gerados por aerogeradores, os impactos causados em aves são os mais intensos. Segundo Greenpeace (2006), em 2001 nos Estados Unidos, 33000 pássaros foram mortos por 15000 turbinas. Esses riscos são intensificados quando há o deslocamento de bandos. O uso de turbinas modernas de baixa velocidade de rotação deve ser incentivado para reduzir ainda esses resultados indesejáveis.

Turbinas aerogeradoras também podem atrapalhar as telecomunicações e gerar riscos as pessoas. Alguns aerogeradores podem gerar interferências eletromagnéticas e interferir em sistemas de telecomunicações, além disso, em casos de descargas elétricas os estilhaços podem ferir pessoas próximas. Mesmo sendo pequenos, esses riscos devem ser levados em consideração no projeto de instalação de um parque eólico (Custódio, 2013).

\subsection{Panorama da energia eólica}

Desde 2013, a potência eólica instalada no mundo vem atingindo patamares consideráveis de crescimento. Segundo o Global Wind Energy Outlook 2014 (GWEO2014), considerado um cenário moderado, em 2013 o potencial eólico mundial foi de 318.128 MW e a previsão para 2050 é que esse valor chegue à 2.672.231 MW. Embora essa energia renovável não seja a principal fonte energética em muitos países, esta apresenta um grande potencial.

Devido a uma maior representatividade, em termos de produção e consumo energético, os cenários: europeu e 
americano podem ser utilizados para avaliar o potencial desta energia renovável. No cenário europeu, um programa audacioso, chamado Europa 2020, ganha destaque por incentivar a utilização de fontes renováveis. Dentre outras propostas que devem entrar em vigor até 2020, esse programa visa aumentar em $20 \%$ a participação de fontes renováveis na matriz energética europeia (Barroso, 2012). O cenário americano, também apresenta indicadores positivos. O Annual Energy Outlook 2013 (AEO2013) faz uma previsão de geração de 42 gigawatts para o periodo compreendido entre 2011 e 2040. O planejamento energético dos grandes consumidores indica uma tendência mundial de diversificação da matriz energética.

O cenário brasileiro também apresenta crescentes investimentos na geração de energia eólica. No início de 2015, o Brasil possuía 6,0 GW de potencia eólica instalada e o planejamento do governo brasileiro, por meio do plano decenal, visa elevar essa potencia para $17 \mathrm{GW}$ até 2022 (Global Wind Energy Council, 2013). Estes dados são indicativos de uma expansão que busca a consolidação no uso dessa fonte.

No cenário piauiense, a potência instalada no Estado corresponde a $293 \mathrm{MW}$. Devido ao surgimento de novos projetos visando à instalação de parques eólicos, a energia eólica vem ganhando destaque no Piauí. No último leilão realizado pelo Ministério de Minas e Energias para fontes alternativas de energia, o estado foi o que mais vendeu. Dos 800 MW comprados no leilão, realizado em novembro de 2014, 240 MW são do Piauí. Os projetos estão previstos para serem instalados na chapada do Araripe, na região compreendida aos municípios de Simões e Marcolândia. Somado a esses se tem $400 \mathrm{MW}$ previstos para serem instalados no município de Caldeirão Grande.

\section{Metodologia}

Todos os dados de direção e velocidade de vento, contidos nesse trabalho foram fornecidos pelo Instituto Nacional de Meteorologia (INMET), medidos em intervalos de uma hora e a $10 \mathrm{~m}$ de altitude em relação ao solo. Para que esses dados pudessem ser analisados e comparados com outras pesquisas, via Windographer ${ }^{\circledR}$, extrapolou-se esses dados para alturas correspondentes a 50, 70 e $90 \mathrm{~m}$ em relação ao nível solo. Os municípios onde se localizam as Plataformas de Coleta de Dados (PCDs) escolhidas para a realização das investigações sobre a caracterização do regime de ventos estão contidos na Tabela 1. Já a Fig. 2 mostra a localização dos municípios no mapa do estado.

O período compreendido para estudo foi de 01 de Janeiro de 2010 à 31 de Dezembro de 2010. Das 19 plataformas de coleta de dados presentes no Piauí, 8 foram utilizadas neste estudo, pois nas demais verificou-se muitos dados inconsistentes e grandes sequências de dados ausentes. Assim o período que apresentou maior consistência e as PCDs com maior quantidade de dados possíveis se serem

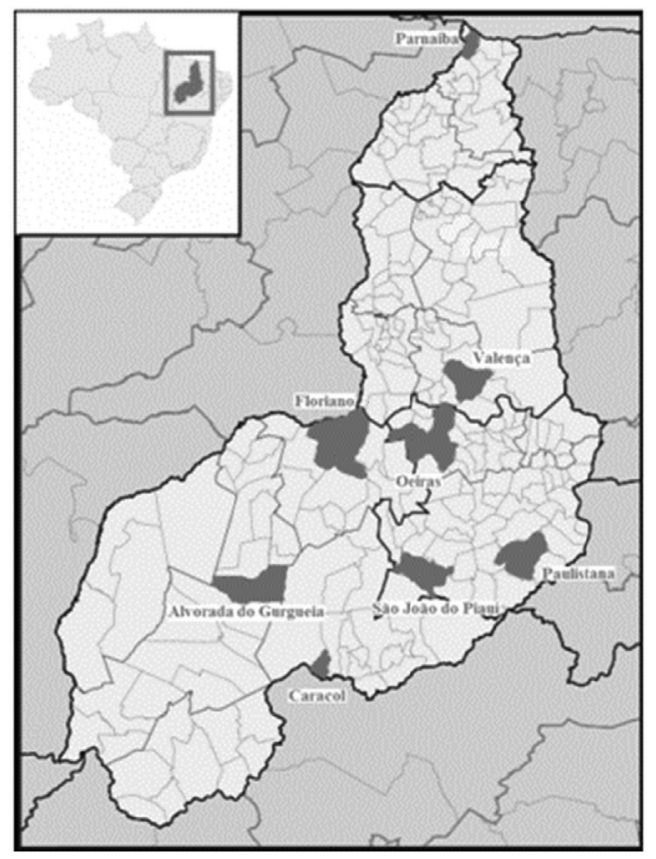

Figura 2 - Localização das plataformas de coletas de dados no mapa do Piauí.

Tabela 1 - Localização das Plataformas de Coleta de Dados.

\begin{tabular}{lccc}
\hline Município & Latitude & Longitude & Altitude \\
\hline Alvorada do Gurgueia & $08^{\circ} 26^{\prime} \mathrm{S}$ & $43^{\circ} 51^{\prime} \mathrm{W}$ & $270 \mathrm{~m}$ \\
Caracol & $09^{\circ} 17^{\prime} \mathrm{S}$ & $43^{\circ} 19^{\prime} \mathrm{W}$ & $523 \mathrm{~m}$ \\
Floriano & $06^{\circ} 46^{\prime} \mathrm{S}$ & $43^{\circ} 01^{\prime} \mathrm{W}$ & $123 \mathrm{~m}$ \\
Oeiras & $06^{\circ} 58^{\prime} \mathrm{S}$ & $42^{\circ} 08^{\prime} \mathrm{W}$ & $156 \mathrm{~m}$ \\
Parnaíba & $03^{\circ} 05^{\prime} \mathrm{S}$ & $41^{\circ} 47^{\prime} \mathrm{W}$ & $79 \mathrm{~m}$ \\
Paulistana & $08^{\circ} 04^{\prime} \mathrm{S}$ & $41^{\circ} 04^{\prime} \mathrm{W}$ & $374 \mathrm{~m}$ \\
São João do Piauí & $08^{\circ} 21^{\prime} \mathrm{S}$ & $42^{\circ} 15^{\prime} \mathrm{W}$ & $235 \mathrm{~m}$ \\
Valença & $06^{\circ} 23^{\prime} \mathrm{S}$ & $41^{\circ} 44^{\prime} \mathrm{W}$ & $301 \mathrm{~m}$ \\
\hline
\end{tabular}

estudados foram escolhidas para a realização deste trabalho.

\subsection{O software Windographer ${ }^{\circledR}$}

Todos os gráficos que representam o perfil horário e mensal de velocidades médias do vento bem como sua direção predominante foram construídos utilizando-se o software Windographer ${ }^{\circledR}$ a partir da inserção dos dados obtidos do INMET.

O Windographer ${ }^{\circledR}$ apresenta várias vantagens, dentre as quais a capacidade de analisar uma grande quantidade de dados de forma otimizada e eficaz, abrir arquivos salvos no Excel, gerar vários gráficos das componentes dos ventos, dando a opção ao usuário de configurar esses gráficos da maneira que lhe for conveniente e ainda mostrar uma tabela com informações de como o programa interpretou cada dado. 


\section{Resultados e Discussões}

Para produzir uma melhor análise dos padrões horários e mensais de velocidade e direção do vento, os resultados foram divididos em função dos municípios.

Considerando-se que os mais recentes geradores eólicos instalados no estado do Ceará, modelo E 701.8 da fabricante Wobben (fonte: WobbenWindpower), possuem em sua curva de potência, uma velocidade de entrada velocidade na qual se tem inicio da geração - de $2,5 \mathrm{~m} / \mathrm{s}$, utilizaremos este valor para análise dos dados apresentados a seguir nos perfis horários e mensais de velocidade dos ventos.

\subsection{Alvorada do Gurgueia}

Na Fig. 3, observa-se o gráfico do perfil da velocidade média horária do vento no município de Alvorada do Gurgueia estimada para as alturas correspondentes a 50, 70 e $90 \mathrm{~m}$ em relação ao nível solo. O gráfico mostra que os maiores valores de velocidade de vento ocorrem entre 13:00 h e 15:00 h, horário local, com máximas de 4,1 m/s; $4,3 \mathrm{~m} / \mathrm{s}$ e $4,5 \mathrm{~m} / \mathrm{s}$ para as respectivas alturas de 50,70 e $90 \mathrm{~m}$. Já os menores valores foram observados entre 8:00 h e 10:00 h, horário local, com mínimas de 1,4 m/s $; 1,5 \mathrm{~m} / \mathrm{s}$ e $1,5 \mathrm{~m} / \mathrm{s}$ para as alturas de 50,70 e $90 \mathrm{~m}$. Segundo o atlas brasileiro de energia eólica (2001), nessa região a velocidade média de vento anual, medida a $50 \mathrm{~m}$ de altura, pode chegar a $6 \mathrm{~m} / \mathrm{s}$.

Em seguida tem-se na Fig. 4 o gráfico da velocidade média mensal dos ventos correspondentes a 50,70 e $90 \mathrm{~m}$ em relação ao nível solo. Nesse gráfico é possível observar que os maiores valores de velocidade média mensal dos ventos foram registrados de julho a setembro, com máximas de $3,5 \mathrm{~m} / \mathrm{s} ; 3,6 \mathrm{~m} / \mathrm{s}$ e $3,7 \mathrm{~m} / \mathrm{s}$ para as respectivas alturas de 50,70 e $90 \mathrm{~m}$. Durante os meses de abril e maio observa-se os menores valores de velocidade média mensal, com mínima de $1,9 \mathrm{~m} / \mathrm{s} ; 2,0 \mathrm{~m} / \mathrm{s} \mathrm{e} 2,1 \mathrm{~m} / \mathrm{s}$ para as alturas de 50,70 e $90 \mathrm{~m}$. Na região onde está localizado esse município, a velocidade média trimestral, no trimestre de

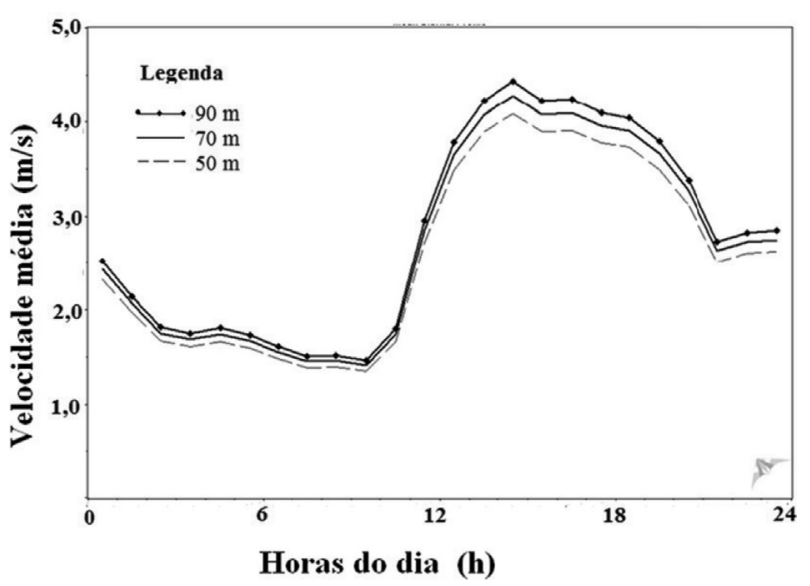

Figura 3 - Perfil da velocidade média horária em Alvorada do Gurgueia.

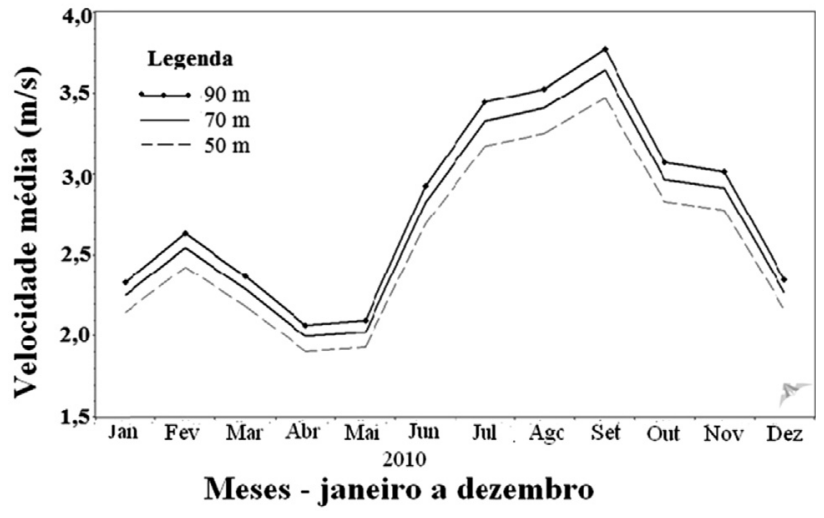

Figura 4 - Perfil da velocidade média mensal em Alvorada do Gurgueia.

junho a agosto, pode chegar a $6,5 \mathrm{~m} / \mathrm{s}$ e no trimestre de menor velocidade média trimestral, março a maio, essa velocidade média pode assumir valores de iguais a $3,5 \mathrm{~m} / \mathrm{s}$ (atlas brasileiro de energia eólica, 2001).

Outro aspecto importante é a direção predominante do vento apresentada pela Fig. 5. Segundo Varejão (2006), quando se deseja implantar turbinas para obter energia eólica, é de grande interesse conhecer tal característica. A direção predominante do vento nesta região é a sudeste, podendo em alguns meses tender para sul. Segundo o atlas brasileiro de energia eólica (2001), embora a direção do vento nessa região varie entre $90^{\circ}$ e $180^{\circ}$, durante os meses de maior intensidade de vento a direção sudeste é predominante.

\subsection{Caracol}

A Fig. 6 mostra o gráfico da velocidade média horária do vento no município de Caracol estimada para as alturas correspondentes a 50, 70 e $90 \mathrm{~m}$ em relação ao nível solo. Com base na figura, é possível observar que os maiores valores de velocidade média horária do vento foram registrados entre 13:00 h e 15:00 h, horário local, com máximas e $5,2 \mathrm{~m} / \mathrm{s} ; 5,5 \mathrm{~m} / \mathrm{s} \mathrm{e} 5,7 \mathrm{~m} / \mathrm{s}$ para as alturas de 50,70 e $90 \mathrm{~m}$. Já os menores valores de velocidade média horária dos

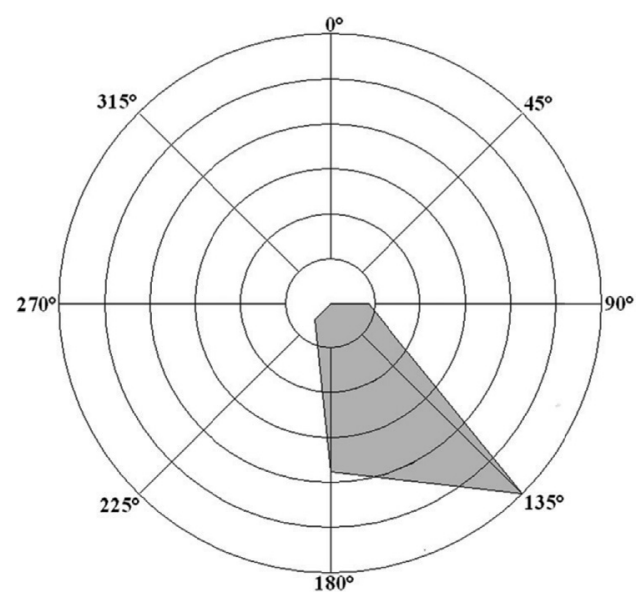

Figura 5 - Direção predominante dos ventos em Alvorada do Gurgueia. 


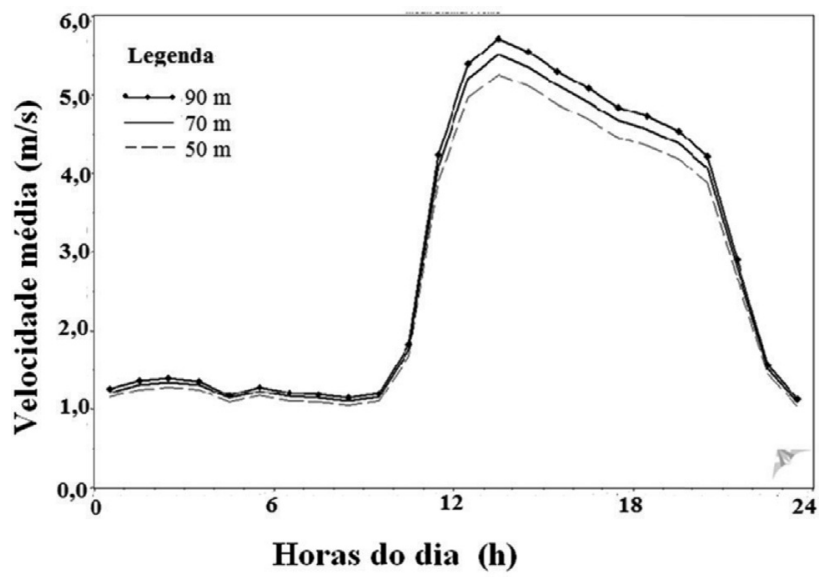

Figura 6 - Perfil da velocidade média horária em Caracol.

ventos podem ser observados entre 6:00 h e 10:00 h, horário local, com mínima de $1,1 \mathrm{~m} / \mathrm{s}$ nas alturas de 50,70 e $90 \mathrm{~m}$. Segundo o atlas brasileiro de energia eólica (2001), a velocidade média anual do vento, a uma altura de $50 \mathrm{~m}$, na região compreendida por esse município pode variar de $5,5 \mathrm{~m} / \mathrm{s}$ a $6 \mathrm{~m} / \mathrm{s}$.

Já na Fig. 7, a qual apresenta o perfil da velocidade média mensal dos ventos correspondentes a 50,70 e $90 \mathrm{~m}$ em relação ao nível solo. Posse observar que os maiores valores de velocidade média mensal do vento ocorreram em julho e em setembro com máximas de $3,7 \mathrm{~m} / \mathrm{s} ; 3,9 \mathrm{~m} / \mathrm{s}$ e $4,0 \mathrm{~m} / \mathrm{s}$ para as respectivas alturas de 50,70 e $90 \mathrm{~m}$ nos meses de julho e setembro. Os menores valores foram registrados nos meses de março a maio com mínimas de $1,8 \mathrm{~m} / \mathrm{s} ; 1,9 \mathrm{~m} / \mathrm{s}$ e $2,0 \mathrm{~m} / \mathrm{s}$, para as alturas de 50,70 e $90 \mathrm{~m}$, no mês de abril. Segundo o atlas brasileiro de energia eólica (2001), na região compreendida pelo município de Caracol, as velocidades trimestrais máximas são observadas entre junho a agosto com valores que podem chegar a $7 \mathrm{~m} / \mathrm{s}$ e mínimas de $3,5 \mathrm{~m} / \mathrm{s}$ no trimestre de março a maio.

Quanto à direção pode-se perceber pela Fig. 8 que no município de Caracol, o vento sofre variações de direção entre $135^{\circ}$ e $180^{\circ}$. Nessa região, a direção predominante dos ventos no período de maior velocidade trimestral, ju-

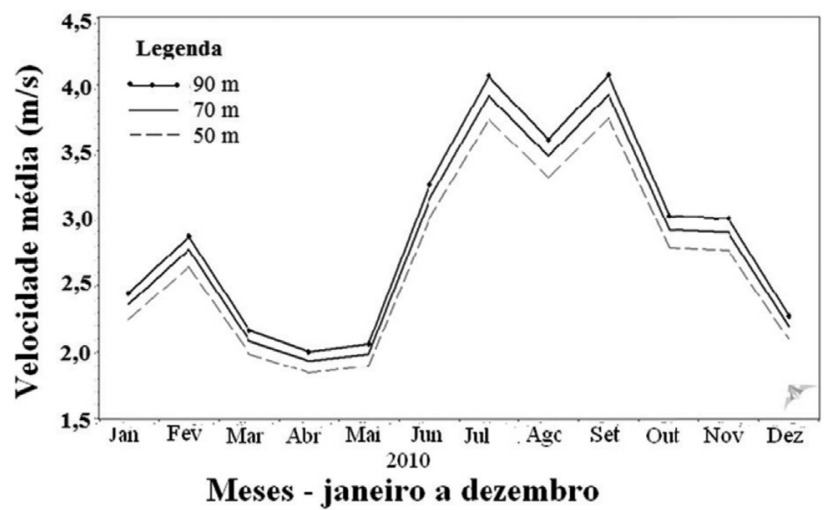

Figura 7 - Perfil da velocidade média mensal em Caracol.

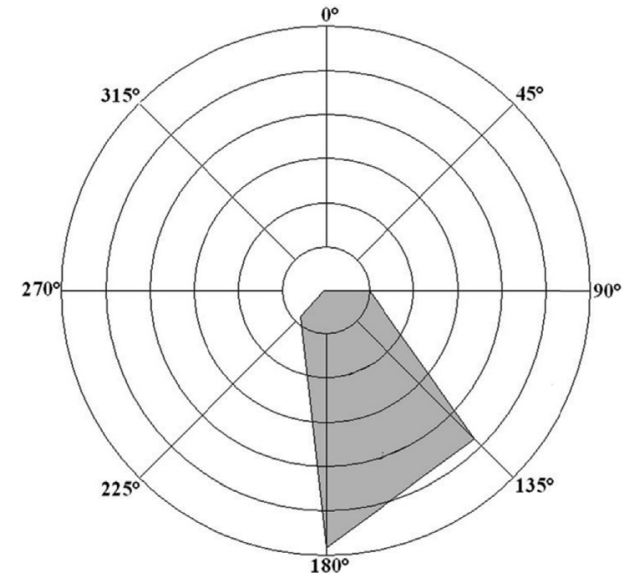

Figura 8 - Direção predominante do vento em Caracol.

nho a agosto, é a sudeste com possíveis variações durante o ano entre $90^{\circ}$ e $180^{\circ}$ (atlas brasileiro de energia eólica, 2001).

\subsection{Floriano}

Na Fig. 9 apresenta o gráfico da velocidade média horária do vento no município de Floriano estimada para as alturas correspondentes a 50,70 e $90 \mathrm{~m}$ em relação ao nível solo. O gráfico mostra que os maiores valores de velocidade média horária do vento foram registrados entre 13:00 h e 15:00 h, horário local. Os valores máximos de velocidade observados foram $3,1 \mathrm{~m} / \mathrm{s} ; 3,3 \mathrm{~m} / \mathrm{s}$ e 3,4 $\mathrm{m} / \mathrm{s}$ para as respectivas alturas de 50,70 e $90 \mathrm{~m}$. Já os menores valores de velocidade média horária do vento ocorrem 24:00 h e 2:00 h, horário local, com mínimas de $1,1 \mathrm{~m} / \mathrm{s} ; 1,2 \mathrm{~m} / \mathrm{s}$ e $1,2 \mathrm{~m} / \mathrm{s}$ para as alturas de 50,70 e $90 \mathrm{~m}$. A região compreendida pelo município de Floriano pode apresentar uma velocidade média anual, media a $50 \mathrm{~m}$ de altura, entre $3,5 \mathrm{~m} / \mathrm{s}$ e $4 \mathrm{~m} / \mathrm{s}$ (atlas brasileiro de energia eólica, 2001).

Já na Fig. 10 têm-se os perfis da velocidade média mensal dos ventos correspondentes a 50,70 e $90 \mathrm{~m}$ em rela-

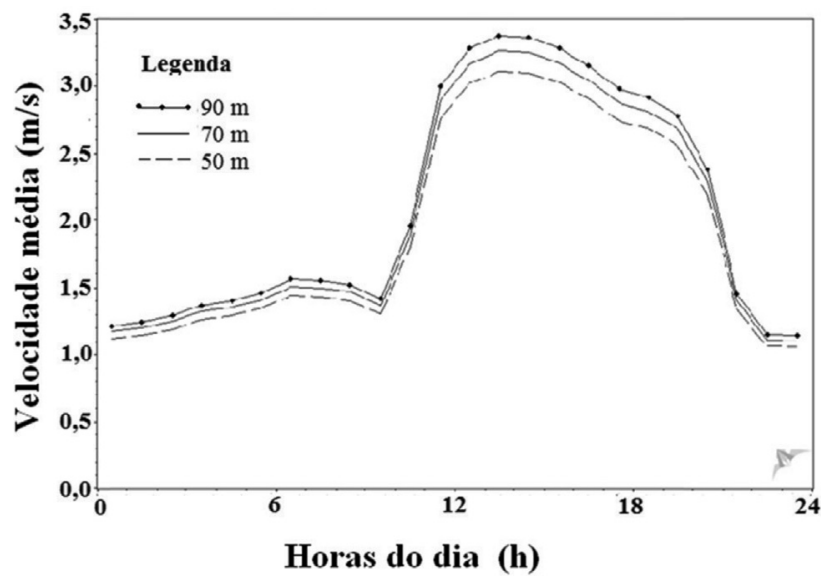

Figura 9 - Perfil da velocidade média horária em Floriano. 


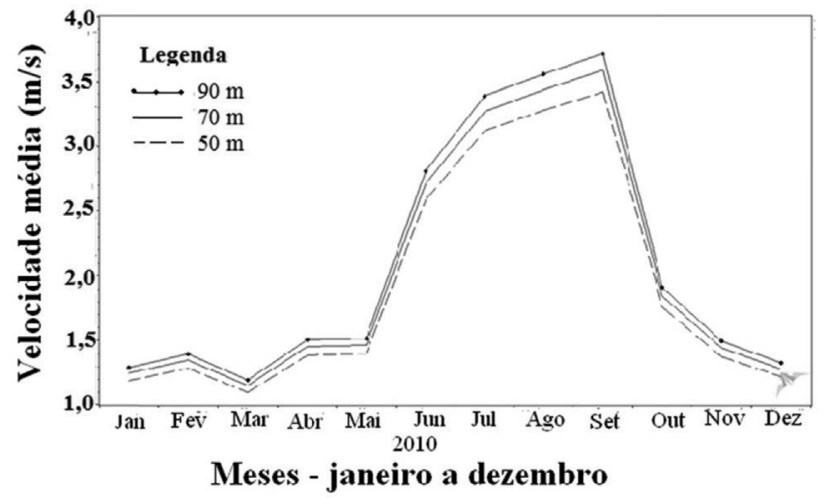

Figura 10 - Perfil da velocidade média mensal em Floriano.

ção ao nível solo. A figura mostra que os maiores valores de velocidade média mensal dos ventos ocorrem entre julho e setembro, com máximas de $3,4 \mathrm{~m} / \mathrm{s} ; 3,5 \mathrm{~m} / \mathrm{s}$ e $3,7 \mathrm{~m} / \mathrm{s}$, no inicio do mês de setembro, para 50, 70 e $90 \mathrm{~m}$. Já os menores valores de velocidade média mensal foram registrados nos meses de dezembro, janeiro e março com mínima de $1,1 \mathrm{~m} / \mathrm{s} ; 1,2 \mathrm{~m} / \mathrm{s}$ e $1,2 \mathrm{~m} / \mathrm{s}$, para as respectivas alturas de 50, 70 e $90 \mathrm{~m}$, no mês de março. Segundo o atlas brasileiro de energia eólica (2001), a região compreendida pelo município de Floriano pode apresentar velocidades médias trimestrais máximas, no período de junho a agosto, de aproximadamente $6,5 \mathrm{~m} / \mathrm{s}$ e mínima de $3,5 \mathrm{~m} / \mathrm{s}$ de janeiro a março.

Na Fig. 11 tem-se representada a direção predominante dos ventos no município de Floriano. A figura mostra que a direção predominante do vento nessa região é a sudeste com algumas oscilações no decorrer do ano entre $90^{\circ}$ e $180^{\circ}$. Segundo o atlas brasileiro de energia eólica (2001), no trimestre correspondente de junho a agosto, período de maior velocidade de vento, tem-se que a direção predominante do vento é a sudeste e durante o ano essa direção sofre variações de entre $45^{\circ}$ e $180^{\circ}$.

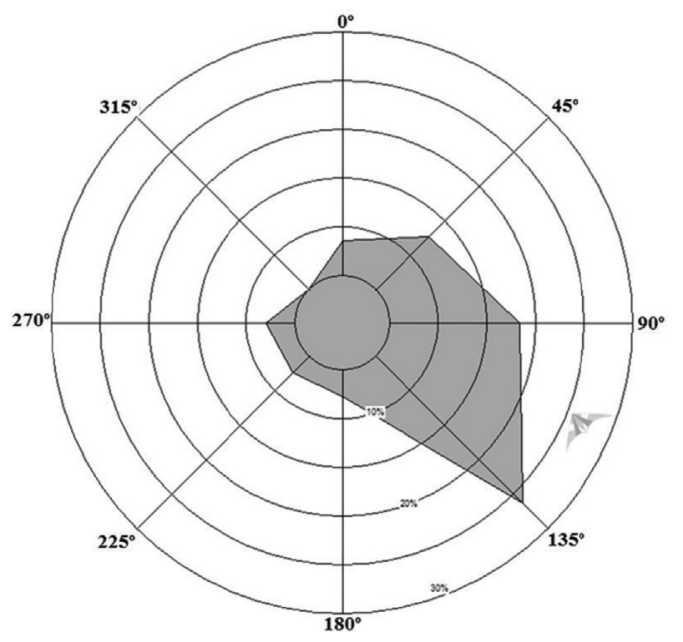

Figura 11 - Direção predominante do vento em Floriano.

\subsection{Oeiras}

A Fig. 12 mostra o gráfico da velocidade média horária do vento no município de Oeiras estimada para as alturas correspondentes a 50,70 e $90 \mathrm{~m}$ em relação ao nível solo. Neste gráfico observa-se que os maiores valores de velocidade do vento ocorre entre 13:00 h e 15:00 h, horário local, com máximas de $4,4 \mathrm{~m} / \mathrm{s} ; 4,5 \mathrm{~m} / \mathrm{s}$ e $4,6 \mathrm{~m} / \mathrm{s}$ nas altitudes de 50,70 e $90 \mathrm{~m}$, respectivamente. Já os menores ocorreram entre 00:00 h e 03:00 h, horário local, com mínimas de $1,4 \mathrm{~m} / \mathrm{s} ; 1,5 \mathrm{~m} / \mathrm{s}$ e $1,6 \mathrm{~m} / \mathrm{s}$ para as alturas de 50 , 70 e $90 \mathrm{~m}$. Segundo o atlas brasileiro de energia eólica (2001), a região abrangida pelo munícipio de Oeiras pode apresentar velocidades médias de vento, medidas a $50 \mathrm{~m}$ de altura, que podem variar de $4,5 \mathrm{~m} / \mathrm{s}$ a $6 \mathrm{~m} / \mathrm{s}$.

Na Fig. 13 esta representada a velocidade média mensal do vento no município de Oeiras estimada para as alturas correspondentes a 50, 70 e $90 \mathrm{~m}$ em relação ao nível solo. Segundo esta figura, os maiores valores de velocidade de vento ocorrem nos meses de julho, agosto e setembro e apresentam máximas de $4,6 \mathrm{~m} / \mathrm{s} ; 4,7 \mathrm{~m} / \mathrm{s}$ e $5,0 \mathrm{~m} / \mathrm{s}$ para as respectivas alturas de 50,70 e $90 \mathrm{~m}$. Já as mínimas velocidades de vento foram registradas nos meses de dezembro, janeiro e março, com mínimas de $1,6 \mathrm{~m} / \mathrm{s} ; 1,7 \mathrm{~m} / \mathrm{s}$ e $1,8 \mathrm{~m} / \mathrm{s}$

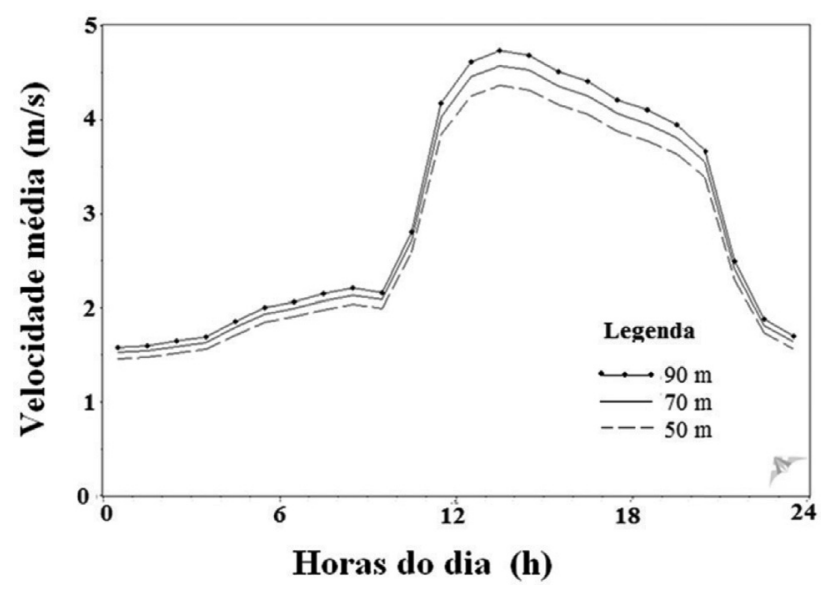

Figura 12 - Velocidade média horária em Oeiras.

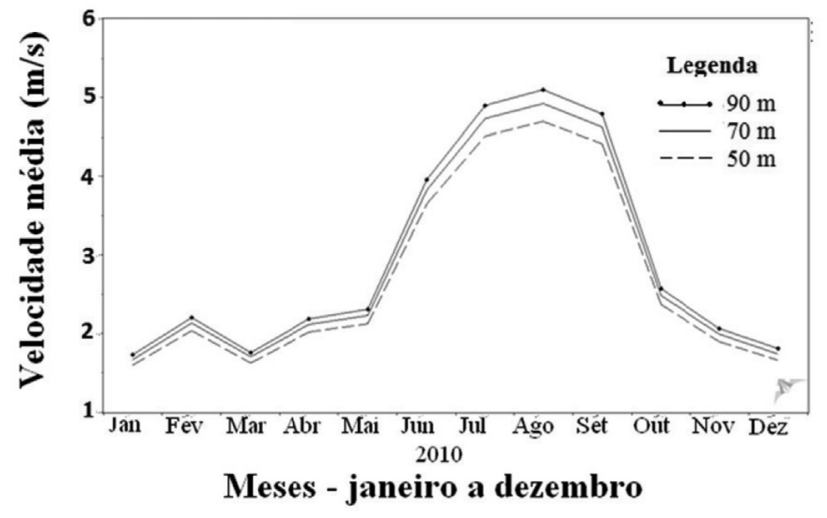

Figura 13 - Perfil da velocidade média mensal em Oeiras. 
para alturas de 50, 70 e $90 \mathrm{~m}$. Nessa região a velocidade média trimestral pode atingir valores máximos de $7,5 \mathrm{~m} / \mathrm{s}$ nos meses de junho a agosto e mínima de $4,5 \mathrm{~m} / \mathrm{s}$ nos meses de dezembro a fevereiro (atlas brasileiro de energia eólica, 2001).

Com relação à direção dos ventos pode-se observar na Fig. 14, que neste município a direção dos ventos pode sofrer variações entre $135^{\circ}$ e $180^{\circ}$. Segundo o atlas brasileiro de energia eólica (2001), embora durante a maior parte do ano a direção dos ventos nesse município varia entre $90^{\circ}$ e $180^{\circ}$, nos meses de maior intensidade de vento, junho a agosto, a direção predominante e é a sudeste.

\subsection{Parnaíba}

Na Fig. 15 está representada a variação da velocidade média horária do vento no município de Parnaíba estimada para as alturas correspondentes a 50, 70 e $90 \mathrm{~m}$ em relação ao nível solo. O gráfico mostra que os maiores valores de velocidade média do vento ocorreram entre às 18:00 h e 20:00 h, horário local, com máxima de aproximadamente $5,5 \mathrm{~m} / \mathrm{s} ; 5,8 \mathrm{~m} / \mathrm{s}$ e $6,1 \mathrm{~m} / \mathrm{s}$ nas altitudes de 50,70 e $90 \mathrm{~m}$,

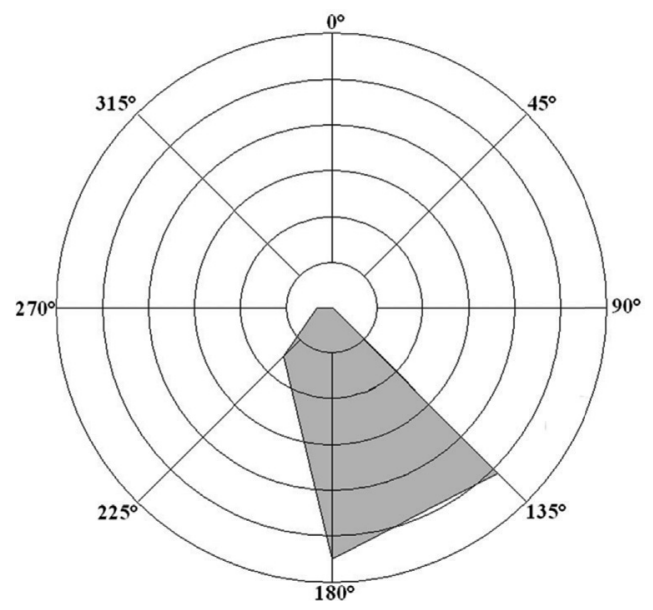

Figura 14 - Direção predominante do vento em Oeiras.

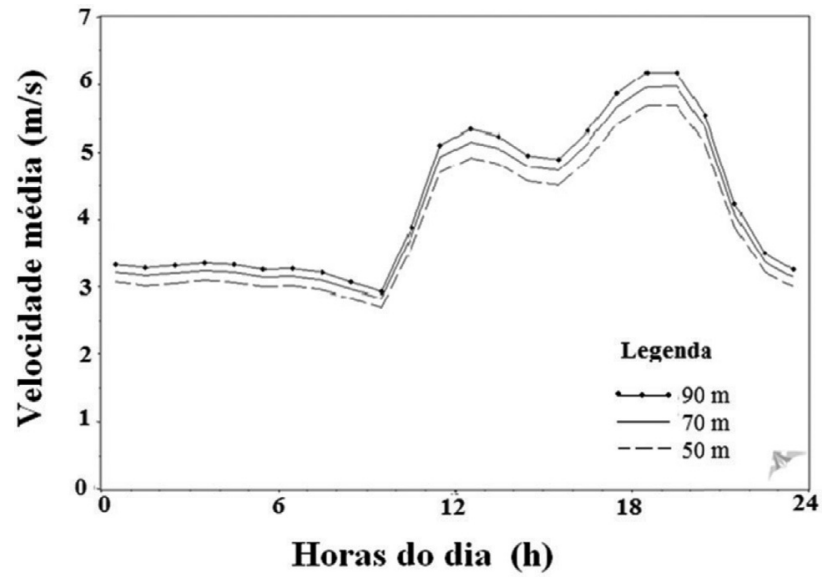

Figura 15 - Perfil da velocidade média horária em Parnaíba. respectivamente. Já os menores valores foram registrados entre 9:00 h e 10:00 h, horário local com mínima de aproximadamente $2,8 \mathrm{~m} / \mathrm{s} ; 2,9 \mathrm{~m} / \mathrm{s} \mathrm{e} 3 \mathrm{~m} / \mathrm{s}$ para as altitudes de 50 , 70 e $90 \mathrm{~m}$. Segundo o atlas brasileiro de energia eólica (2001), a região compreendida pelo município de Parnaíba apresenta uma velocidade média anual de vento, a $50 \mathrm{~m}$ de altura, que pode variar entre $6 \mathrm{~m} / \mathrm{s}$ e $7,5 \mathrm{~m} / \mathrm{s}$. Devido à ocorrência dos maiores valores de velocidade, durante a noite e as primeiras horas do dia, pode-se inferir que nesse município a brisa terrestre exerce forte influência.

A Fig. 16 apresenta os valores da velocidade média mensal do vento no município de Parnaíba estimada para as alturas correspondentes a 50, 70 e $90 \mathrm{~m}$ em relação ao nível solo. O gráfico mostra três períodos bem definidos. O primeiro, entre janeiro e março, apresenta velocidades que podem chegar a $4,5 \mathrm{~m} / \mathrm{s} ; 4,8 \mathrm{~m} / \mathrm{s} 5 \mathrm{~m} / \mathrm{s}$, respectivamente para alturas de 50,70 e $90 \mathrm{~m}$. O segundo, entre os meses de abril e julho, apresenta os menores valores de velocidade, com mínimas de $2,4 \mathrm{~m} / \mathrm{s} ; 2,5 \mathrm{~m} / \mathrm{s}$ e $2,6 \mathrm{~m} / \mathrm{s}$ para as altitudes de 50,70 e $90 \mathrm{~m}$. E o terceiro, compreendido entre os meses de agosto e dezembro, em que foram registradas as maiores médias de velocidade, com máximas de $5,5 \mathrm{~m} / \mathrm{s} ; 5,7 \mathrm{~m} / \mathrm{s}$ e $6 \mathrm{~m} / \mathrm{s}$ para 50,70 e $90 \mathrm{~m}$, respectivamente. Segundo o atlas brasileiro de energia eólica (2001), a região compreendida pelo município de Parnaíba pode apresentar velocidades médias trimestrais máximas que podem variar entre $7,5 \mathrm{~m} / \mathrm{s}$ e $8,5 \mathrm{~m} / \mathrm{s}$ nos meses de setembro à novembro e mínimas que podem variar de $3,5 \mathrm{~m} / \mathrm{s}$ à $4,5 \mathrm{~m} / \mathrm{s}$ nos meses de março a maio.

Na Fig. 17, encontra-se representado que a direção predominante dos ventos no município de Parnaíba. A figura mostra que a direção do vento nesse municio sofre variações de $45^{\circ}$ à $90^{\circ}$. Segundo o atlas brasileiro de energia eólica (2001), nos meses de setembro a novembro, período em que se registrou as maiores velocidades de vento na região, observa-se uma variação aproximada da direção do vento de $45^{\circ}$ à $55^{\circ}$. Esta direção está associada à presença dos ventos alísios e às brisas, presentes na região de maneira mais intensa. Esta constatação está de acordo com Alcântara (2008), o qual afirma que no Nordeste do

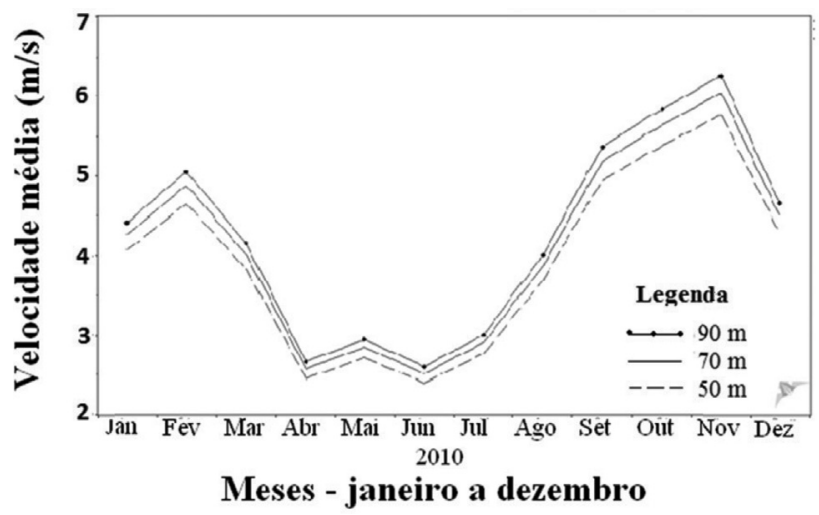

Figura 16 - Perfil da velocidade média mensal em Parnaíba. 


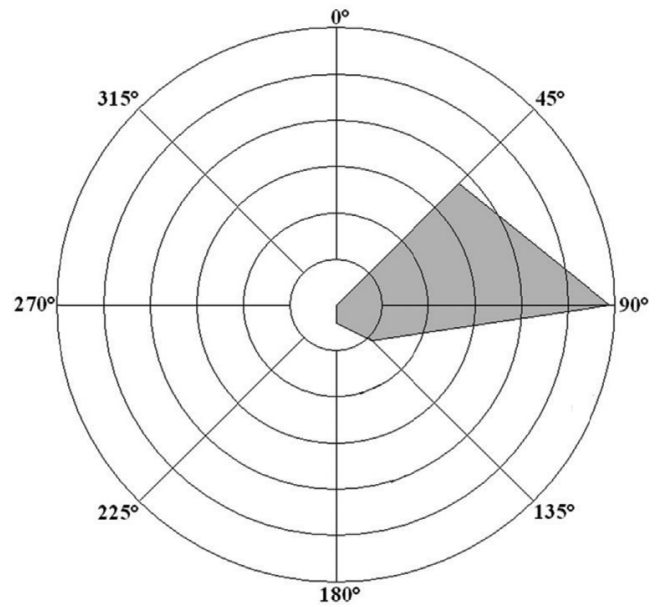

Figura 17 - Direção predominante do vento em Parnaíba.

Brasil, onde os ventos alísios são persistentes e intensos durante todo o ano, quase sempre as brisas apenas contribuem para mudar um pouco a direção e a velocidade dessas. Dependendo da orientação da costa, a velocidade do vento, resultante da superposição alísio-brisa, pode ser maior ou menor que a do alísio.

\subsection{Paulistana}

A Fig. 18 apresenta a variação da velocidade média horária do vento no município de Paulistana estimada para as alturas correspondentes a 50, 70 e $90 \mathrm{~m}$ em relação ao nível solo. Os maiores valores ocorreram entre 11:00 h e 14:00 h. Nesse intervalo registrou-se valores máximos de aproximadamente $5,8 \mathrm{~m} / \mathrm{s}, 6,2 \mathrm{~m} / \mathrm{s}$ e $6,5 \mathrm{~m} / \mathrm{s}$ nas altitudes de 50,70 e $90 \mathrm{~m}$, respectivamente. A velocidade mínima ocorreu às $00: 00 \mathrm{~h}$, horário em que registrou-se velocidades de aproximadamente $3 ; 3,1$ e $3,2 \mathrm{~m} / \mathrm{s}$, respectivamente para alturas de 50,70 e $90 \mathrm{~m}$. Segundo o atlas brasileiro de energia eólica (2001), o município de paulistana está localizado numa região na qual a velocidade média anual do vento, a $50 \mathrm{~m}$ de altura, varia entre 4,5 e $6 \mathrm{~m} / \mathrm{s}$. Nesse estudo registrou-se uma média experimental de aproximadamente

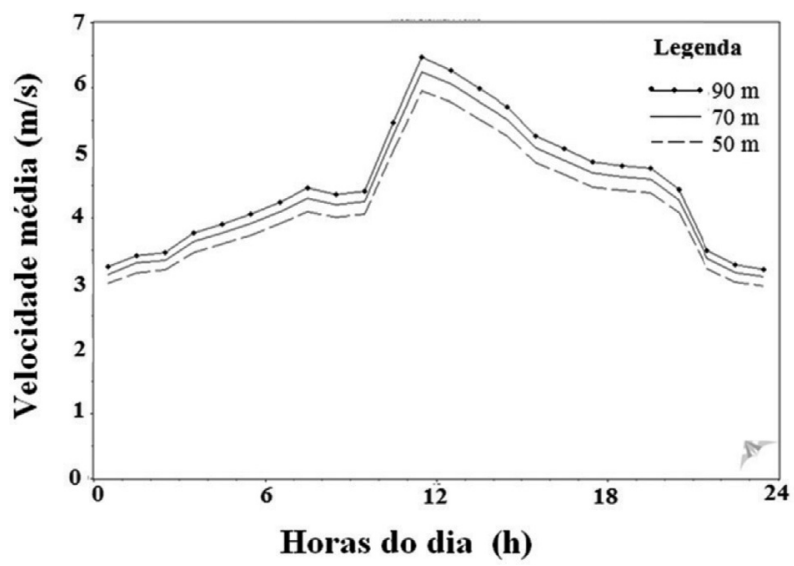

Figura 18 - Perfil da velocidade média horária em Paulistana.
4,2 m/s. Estudos similares (Oliveira, 2007; Barreto et al.), também destacam o grande potencial eólico desta região. Uma explicação para estes valores de velocidade de vento é que o município está situado em um local de elevada altitude em plena Chapada do Araripe (cerca de $374 \mathrm{~m}$ ).

Na Fig. 19, encontra-se representado o perfil das velocidades médias mensais do vento para alturas de 50,70 e $90 \mathrm{~m}$ em relação ao solo. Baseado na análise desta figura, constatou-se que os maiores valores de velocidade média mensal de vento ocorreram entre os meses de julho a setembro. Durante esse período, os máximos valores registrados foram de aproximadamente $6 ; 6,2$ e $6,5 \mathrm{~m} / \mathrm{s}$, respectivas para alturas de 50, 70 e $90 \mathrm{~m}$. Já os menores valores de velocidade média ocorreram entre os meses de dezembro e janeiro e em meados de março, com mínima de $2,3 \mathrm{~m} / \mathrm{s}$ para $50 \mathrm{~m}$, no mês de dezembro. Segundo o atlas brasileiro de energia eólica (2001), o menor valor de velocidade média trimestral de vento a $50 \mathrm{~m}$ de alturas ocorre de dezembro a fevereiro com mínima de aproximadamente $3,5 \mathrm{~m} / \mathrm{s}$. Nesse trabalho constatou-se que durante os meses de dezembro a fevereiro a velocidade média trimestral atinge seu menor valor de $3,7 \mathrm{~m} / \mathrm{s}$. Já os maiores valores foram observados no trimestre de junho a agosto. Os maiores valores de velocidade média trimestral variam de 6 a $8 \mathrm{~m} / \mathrm{s}$ (atlas brasileiro de energia eólica, 2001).

Quanto à variação da direção da velocidade dos ventos, representada pela Fig. 20, constata-se que a direção predominante é a sudeste, entretanto uma parcela dos dados analisados, mostram que em alguns meses essa direção pode variar de $90^{\circ}$ à $135^{\circ}$. Segundo o atlas brasileiro de energia eólica(2001), a direção predominante de vento no trimestre de junho a agosto, período de maior intensidade de vento, é aproximadamente de sudeste e nos outros meses registra-se direções predominantes correspondentes ao intervalo de $90^{\circ}$ à $135^{\circ}$.

\subsection{São João do Piauí}

O gráfico da Fig. 21 mostra a variação da velocidade média horária do vento no município de São João do Piaú

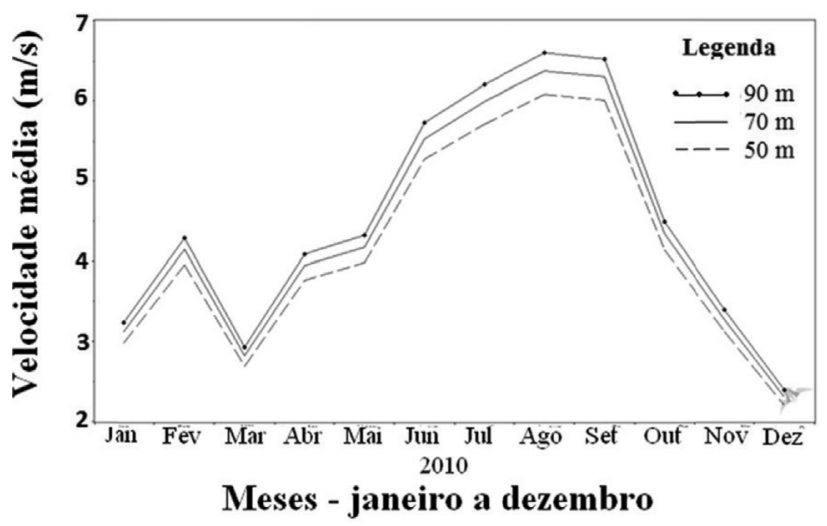

Figura 19 - Perfil da velocidade média mensal em Paulistana estimada para 50,70 e $90 \mathrm{~m}$. 


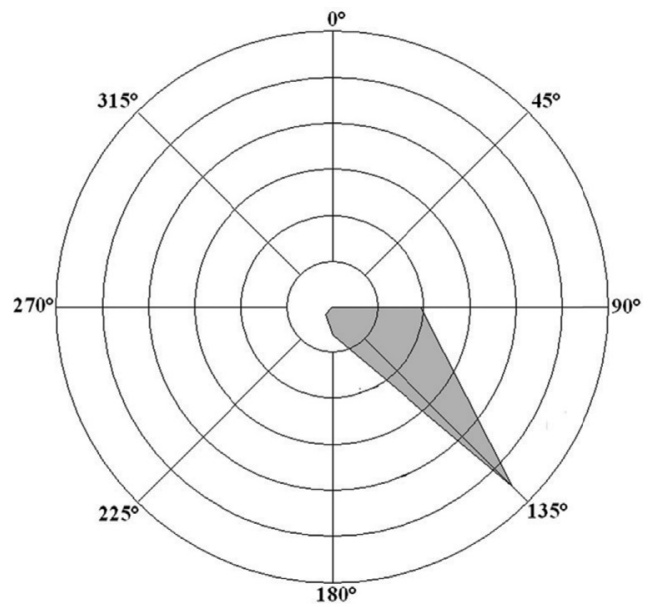

Figura 20 - Direção predominante do vento em Paulistana.

estimada para as alturas correspondentes a 50, 70 e $90 \mathrm{~m}$ em relação ao nível solo. O gráfico mostra que entre 12:00 h e 4:00 h, horário local, tem-se os maiores valores de velocidade de vento com uma máxima, as 12:00 h, de aproximadamente $4,0 \mathrm{~m} / \mathrm{s} ; 4,4 \mathrm{~m} / \mathrm{s} ; 4,5 \mathrm{~m} / \mathrm{s}$ para as alturas correspondentes a 50,70 e $90 \mathrm{~m}$, respectivamente. Já os menores valores de velocidade de vento foram registrados entre 00:00 h e 9:00 h, horário local, assumindo valores mínimos de $1,5 \mathrm{~m} / \mathrm{s} ; 1,6 \mathrm{~m} / \mathrm{s} ; 1,7 \mathrm{~m} / \mathrm{s}$ para as alturas de 50,70 e $90 \mathrm{~m}$. Segundo o atlas brasileiro de energia eólica (2001), a região correspondente ao município de São João do Piauí pode apresentar uma velocidade média anual de vento a $50 \mathrm{~m}$ de altura que pode variar entre $4 \mathrm{~m} / \mathrm{s}$ e $5,5 \mathrm{~m} / \mathrm{s}$.

A Fig. 22 apresenta a variação das velocidades médias mensais de vento para alturas de 50,70 e $90 \mathrm{~m}$ em relação ao solo. Os gráficos mostram que os maiores valores de velocidade de vento foram observados junho a agosto com máximas de $4,1 \mathrm{~m} / \mathrm{s} ; 4,3 \mathrm{~m} / \mathrm{s}$ e $4,4 \mathrm{~m} / \mathrm{s}$ para as respectivas alturas de 50,70 e $90 \mathrm{~m}$. Durante os meses de junho, julho e agosto têm-se os maiores valores de velocidade média trimestral de vento, medida a $50 \mathrm{~m}$ de altura,

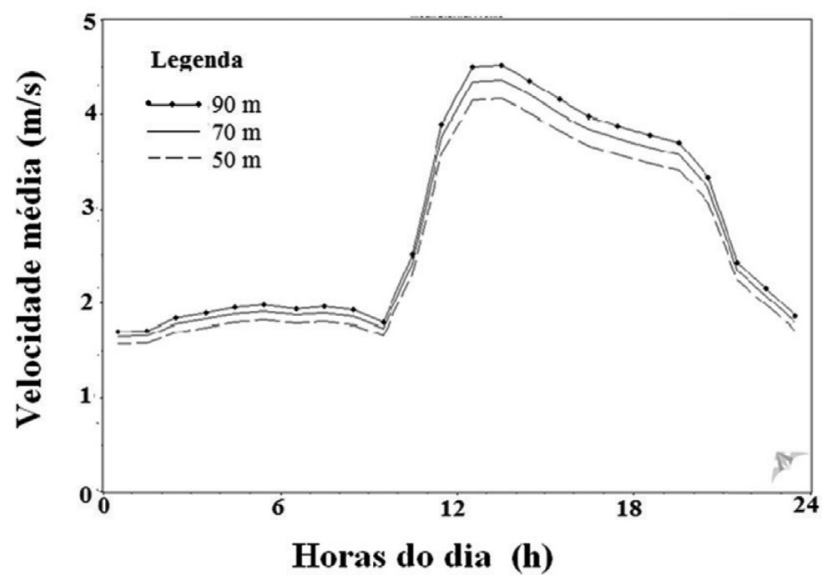

Figura 21 - Perfil da velocidade média horária em São João do Piauí.

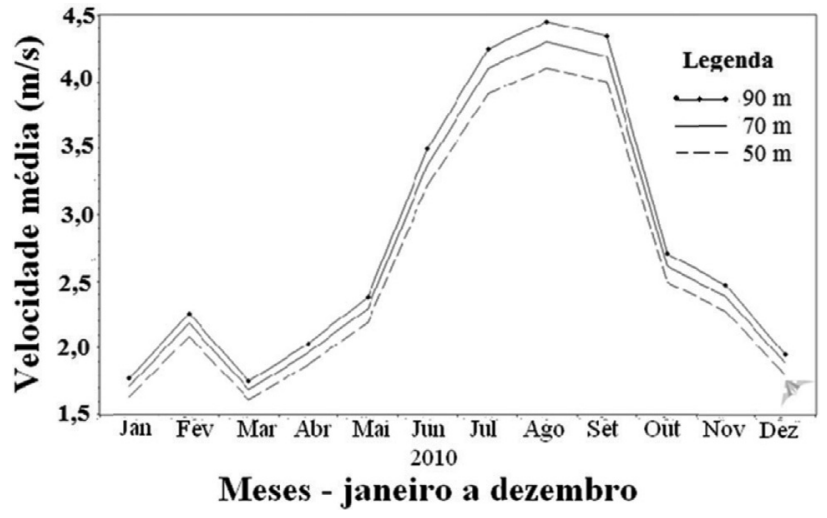

Figura 22 - Perfil da velocidade média mensal em São João do Piauí.

com valores que podem chegar a $7,5 \mathrm{~m} / \mathrm{s}$ (atlas brasileiro de energia eólica, 2001). Já os menores valores foram observados nos meses de dezembro, janeiro e março, com mínima de $1,6 \mathrm{~m} / \mathrm{s} ; 1,7 \mathrm{~m} / \mathrm{s}$ e $1,8 \mathrm{~m} / \mathrm{s}$ para alturas de 50,70 e $90 \mathrm{~m}$, respectivamente. Segundo o atlas brasileiro de energia eólica (2001), os menores valores de velocidade média trimestral, medidos a $50 \mathrm{~m}$, atingem $3,5 \mathrm{~m} / \mathrm{s}$.

A Fig. 23 mostra que a direção do vento predominante no município de São João do Piauí é de sudeste, entretanto, vale ressaltar que em alguns meses essa direção pode oscilar entre valores próximos à $135^{\circ}$ tendendo para a direção sul. Embora essa região apresente direções de vento que oscilam entre $90^{\circ}$ e $180^{\circ}$, durante os meses de junho a agosto, período de maior velocidade de vento, a direção predominante é a sudeste (atlas brasileiro de energia eólica, 2001).

\subsection{Valença}

Na Fig. 24 está representado o gráfico da variação da velocidade média horária do vento no município de Valença estimada para as alturas correspondentes a 50,70 e $90 \mathrm{~m}$ em relação ao nível solo. Os gráficos apresentados nessa figuram mostram que os maiores valores de velocidade de

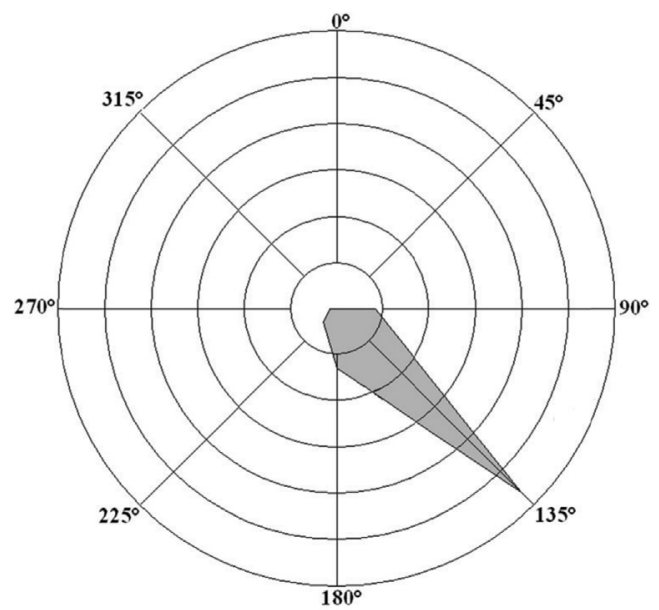

Figura 23 - Direção predominante do vento em São João do Piauí. 


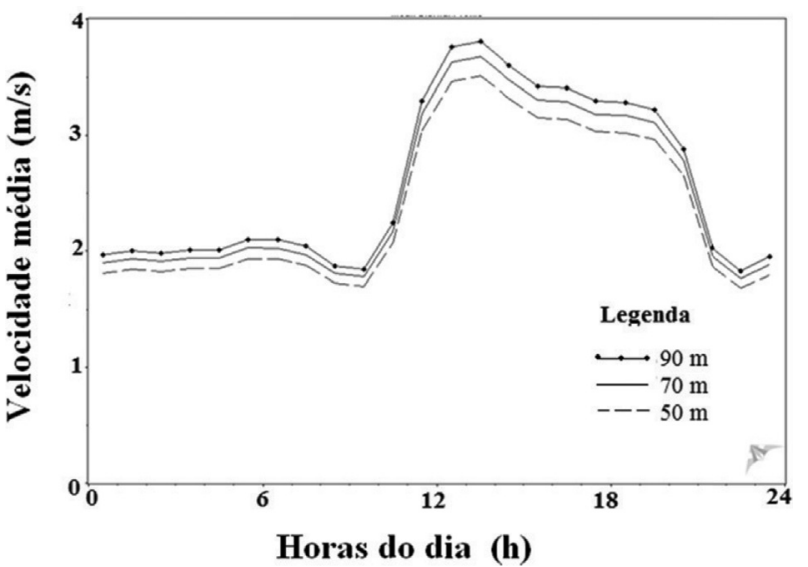

Figura 24 - Perfil da velocidade média horária em Valença.

vento foram registrados entre 13:00 h e 15:00 h, horário local, com máximas de $3,4 \mathrm{~m} / \mathrm{s} ; 3,6 \mathrm{~m} / \mathrm{s}$ e $3,8 \mathrm{~m} / \mathrm{s}$ para as alturas de 50,70 e $90 \mathrm{~m}$, respectivamente. Já os menores valores foram registrados entre as 23:00 h e 10:00 h, horário local, com mínimas de $1,8 \mathrm{~m} / \mathrm{s} ; 1,9 \mathrm{~m} / \mathrm{s}$ e $2,0 \mathrm{~m} / \mathrm{s}$ respectivamente para as alturas de 50,70 e $90 \mathrm{~m}$. Segundo o atlas brasileiro de energia eólica (2001), na região onde está localizado o município de Valença a velocidade média anual do vento, medida a $50 \mathrm{~m}$ de altura, pode variar entre $3,5 \mathrm{~m} / \mathrm{s}$ e $4,5 \mathrm{~m} / \mathrm{s}$.

A Fig. 25 que representa a variabilidade da velocidade média mensal dos ventos. Nos meses de junho, julho, agosto e início de setembro observa-se as maiores velocidades de vento, com máximas de $3,4 \mathrm{~m} / \mathrm{s} ; 3,5 \mathrm{~m} / \mathrm{s}$ e $3,7 \mathrm{~m} / \mathrm{s}$ s para as alturas de 50,70 e $90 \mathrm{~m}$, respectivamente. Já os menores valores foram registrados nos meses de dezembro, janeiro e março com mínimas de $1,6 \mathrm{~m} / \mathrm{s} ; 1,7 \mathrm{~m} / \mathrm{s} \mathrm{e} 1,8 \mathrm{~m} / \mathrm{s}$. A região em que está localizada o município de Valença pode apresentar valores máximos de velocidade média trimestral, medidas a $50 \mathrm{~m}$ de altura, de $4, \mathrm{~m} / \mathrm{s}$ a $5 \mathrm{~m} / \mathrm{s}$ de junho a agosto e mínimas de aproximadamente $3,5 \mathrm{~m} / \mathrm{s}$ nos meses de dezembro a maio (atlas brasileiro de energia eólica, 2001).

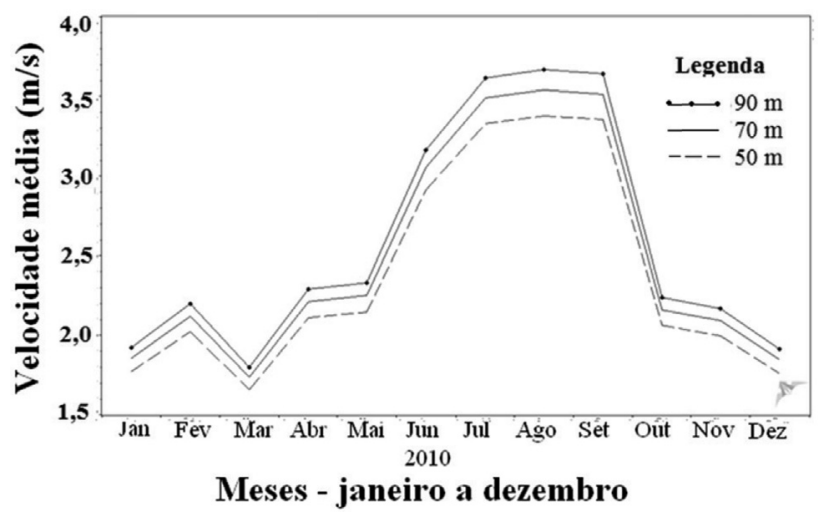

Figura 25 - Perfil da velocidade média mensal em Valença.
Quanto à direção dos ventos, a Fig. 26 mostra que neste município o vento tem direção predominante de sudeste, podendo em alguns períodos curtos de tempo, oscilar entre valores próximos de $135^{\circ}$. Segundo o atlas brasileiro de energia eólica (2001), a direção do vento nessa região pode oscilar entre $90^{\circ}$ e $180^{\circ}$ e nos meses de maior velocidade de vento, junho a agosto, a direção predominante é a sudeste.

\section{Considerações Finais}

Diante do exposto ao longo deste estudo, verifica-se que os municípios analisados podem constituir três grupos distintos pelas características do perfil do vento que apresentam.

Os municípios de Valença e Floriano apresentaram os menores valores de velocidade média horária e mensal de vento. Para alturas de 50, 70 e $90 \mathrm{~m}$, registrou-se valores máximos de velocidade média horária de $3,4 \mathrm{~m} / \mathrm{s}, 3,6 \mathrm{~m} / \mathrm{s} \mathrm{e}$ $3,8 \mathrm{~m} / \mathrm{s}$ respectivamente. E velocidades médias mensais que podem chegar a $3,4 \mathrm{~m} / \mathrm{s}, 3,5 \mathrm{~m} / \mathrm{s}, 3,7 \mathrm{~m} / \mathrm{s}$ para as alturas de 50,70 e $90 \mathrm{~m}$. Além disso, observou-se que a direção predominante nos dois municípios é a sudeste. Embora estes valores não sejam os melhores registrados, a geração eólica não está descartada.

Nos municípios de Oeiras, Caracol, São João do Piauí e Alvorada do Gurgueia foram registrados valores intermediários de velocidade média horária e mensal de vento. Para as alturas de 50,70 e $90 \mathrm{~m}$, os maiores valores de velocidade média horária chegaram a 5,2, m/s, $5,5 \mathrm{~m} / \mathrm{s}, 5,7 \mathrm{~m} / \mathrm{s}$ enquanto que os maiores valores de velocidade média mensal chegaram a 4,6 m/s, 4,7 m/s, 5,0 m/s. Para todos os municípios a direção predominante é a sudeste. Em uma perspectiva de produção energia eólica, estes valores são significativos.

Já nos municípios de Paulistana e Parnaíba, registrou-se os melhores valores de velocidade média horária e mensal do vento. Para alturas de 50, 70 e $90 \mathrm{~m}$, os maiores valores de velocidade média horária atingiram $5,8 \mathrm{~m} / \mathrm{s}$,

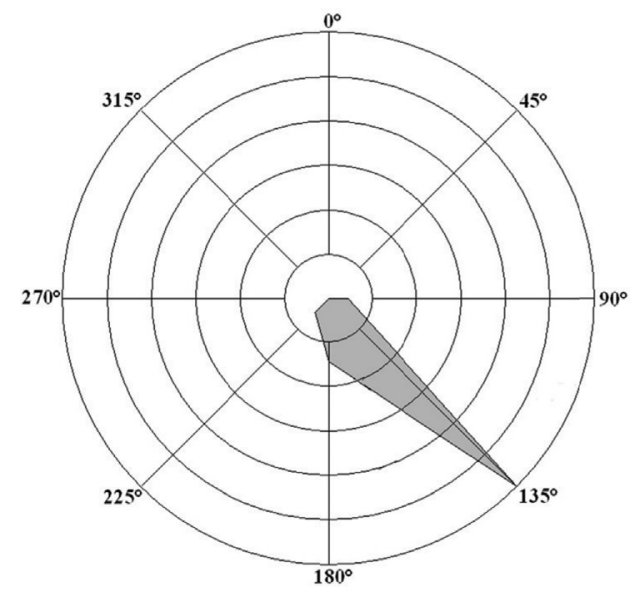

Figura 26 - Direção predominante do vento em Valença. 
$6,2 \mathrm{~m} / \mathrm{s}$ e $6,5 \mathrm{~m} / \mathrm{s}$ e as velocidades médias mensais chegaram a $6,0 \mathrm{~m} / \mathrm{s}, 6,2 \mathrm{~m} / \mathrm{s}, 6,5 \mathrm{~m} / \mathrm{s}$ respectivamente. Já a direção predominante do vento nas duas regiões é diferente. Em Parnaíba a direção varia entre $45^{\circ}$ e $55^{\circ}$ e em Paulistana a direção predominante é a sudeste. Assim, esses dois municípios são recomendados para a instalação de parques eólicos. Não por acaso os atuais parque eólicos situados no Estado estão localizados no entorno destes dois municípios.

Desta forma, conclui-se que o estado do Piauí possui regiões favoráveis para o aproveitamento da energia eólica. Porém, pelo fato deste tipo de energia ser intermitente, este potencial deve ser aproveitado em complementaridade à energia hidrelétrica.

Embora com pequena quantidade de valores ausentes e outros inconsistentes no período estudado, a base de dados utilizada atendeu aos objetivos a que se propunha, no entanto dados de melhor qualidade do ponto de vista da confiabilidade e medidos em maior variedade de locais são sempre desejáveis.

A construção de parques eólicos na perspectiva do desenvolvimento pode ajudar um país a alcançar suas metas econômicas sem necessariamente aumentar seu consumo de combustíveis fósseis, opção fortemente marcante no crescimento de alguns países desenvolvidos. Características socioeconômicas de muitas regiões, como alto desemprego, falta de alternativas de desenvolvimento econômico e altas taxas de migração da população economicamente ativa, fazem com que seja vantajoso o investimento nesses empreendimentos. Em geral, quantifica-se apenas a energia elétrica produtível por uma usina eólica, quando o ideal seria que se quantificassem também os impactos pela emissão de $\mathrm{CO}_{2}$. Uma técnica que pode auxiliar nesta tarefa é um estudo da Avaliação do Ciclo de Vida (ACV) onde são quantificados os impactos globais de uma turbina bem como de todos seus componentes. A ACV também permite fazer uma análise dos casos que produzem maior impacto e os aspectos que poderiam ser melhorados na perspectiva de diminuir efetivamente este impacto.

Para trabalhos futuros sugere-se a análise do potencial de energia elétrica produzida a partir desta fonte.

\section{Referências}

ALCÂNTARA, C.R.; SOUZA, E.P. Uma teoria termodinâmica para brisas: testes utilizando simulações numéricas. Rev. Bras. Meteor. v.23, n.1, p.1-1. 1, março, 2008.

AMARANTE, O.A.; BROWER, M.; ZACK, J.; SÁ, A.L. Atlas do potencial eólico brasileiro. Brasília: MME; Rio de Janeiro: Eletrobrás, 2001. Disponível em: http://www.cresesb.cepel.br/publicacoes/download/at- las eolico/At-

las $\% 20 \mathrm{do} \% 20$ Potencial $\% 20$ Eolico $\% 20$ Brasileiro.pdf.

Acessado em: 15 maio. 2015.

ASSOCIAÇÃO BRASILEIRA DE ENERGIA EÓLICA (ABEEólica), Wind Energy in The Northeast of Brazil, http://www.brazilcouncil.org/sites/de-

fault/files/Webinar\%20RE\%20in\%20Brazil\%20Dorival.pd

f. Acessado em: 05 abril. 2015.

ASSOCIAÇÃO BRASILEIRA DE ENERGIA EÓLICA (ABEEÓLICA), http://www.portalabeeolica.org.br/. Acessado em: 02 abril. 2015.

BARROSO, J.M. Energia: prioridades para a Europa. Disponível em http://ec.europa.eu/europe2020/pdf/energy pt.pdf. Acesso em: 12 janeiro 2015 .

BERG, V.D. The Sound of High Winds: The Effect of Atmospheric Stability on Wind Turbine Sound and Microphone Noise. Ph.D. Dissertation, University of Groningen, 2006.

CASTRO, R.M.G. Energias Renováveis e Produção Descentralizada: introdução à energia eólica. 3 ed. Lisboa, Universidade Técnica de Lisboa, 2007.

Dobriansky, P. Energia limpa para o futuro. Revista e Jornal USA: Perspectivas Econômicas, Washington, D.C, v 11, n. 2, 4-6, 2006.

CUSTÓDIO, R.S. Energia Eólica para produção de energia elétrica. Rio de Janeiro, 2013, 265 p.

DUTRA, R. M. Energia Eólica: Estado de Arte e Princípios Físicos. Rio de Janeiro. Disponível em http://www.cresesb.cepel.br/apresentacoes/20100705_Tec nologia_Eolica_(2010_updates).pdf. Acesso em: 29 maio 2012.

GLOBAL WIND ENERGY COUNCIL. Global Wind Report. Annual Market Update, 2013.

GREENPEACE, Global Wind Energy Outlook, 2006.

GREENPEACE, Global Wind Energy Outlook, 2014.

LÓPES, J.M.E. Manual de Energía Eólica. Ediciones MundiPrensa, Madrid e México, $2^{\mathrm{a}}$ ed, 2011.

MARTIN, F.R.; GUARNIERI, R.A.; PEREIRA, E.B. O aproveitamento da energia eólica. Revista Brasileira de Ensino de Física, São Paulo, v. 30, n. 1, março, 2008.

OMETTO, J.C. Bioclimatologia Vegetal. São Paulo, SP. Agronômica "Ceres". 1981.

PINTO, M.O. Fundamentos de Energia Eólica. Rio de Janeiro, LTC, 2013, $30 \mathrm{p}$.

SILVA, G.R. Panorama do potencial eólico no Brasil. Ed. rev. Brasília: Dupligráfica, 2003.

U.S. ENERGY INFORMATION ADMINISTATION, Annual Energy Outlook (AEO), 2013.

VAREJÃO, M.A. Meteorologia e Climatologia. Pernambuco: Versão Digital 2, 2006.

This is an Open Access article distributed under the terms of the Creative Commons Attribution Non-Commercial License which permits unrestricted non-commercial use, distribution, and reproduction in any medium provided the original work is properly cited. 